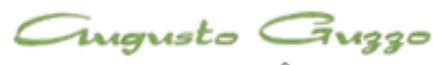

REVISTA ACADEMICA

\title{
A Importância do Legislador no Contrato Social
}

\author{
Jorge Marques Pontes ${ }^{1}$
}

Recebido em: 05/09/2013. Aprovado em: 04/12/2013. Disponibilizado em: 20/12/2013

1. Jorge Marques Pontes é Mestrando em Políticas Públicas na UMC, Graduado em Filosofia, Especialista em Gestão Pública e. Servidor da Fundação Jorge Duprat Figueiredo de Segurança e Medicina no Trabalho - FUNDACENTRO. E-mail: jorge.pontes@live.com.

\section{Resumo}

Rousseau é o filósofo que desenvolveu, em sua obra "Do Contrato Social: princípios do direito político", o ideal de um estado de natureza e sua passagem à sociedade civil, que se desdobra, conjuntamente, com uma investigação do conceito de lei e da função e importância do legislador para a construção de uma sociedade justa e legítima. Na justificativa de algumas de suas posições politico-filosóficas na obra, o filósofo faz citações de fatos e obras de pensadores e estadistas como Montesquieu, Platão, Maquiavel, Sólon e Licurgo. O objetivo nesta pesquisa é desvendar a importância que advém das funções legiferante e pedagógica do legislador no Contrato Social, buscando exemplos nas fontes apontadas na obra rousseauísta.

Palavras-chave: Rousseau. Legislador. Leis. Contrato Social. Montesquieu. Maquiavel. Sólon. Licurgo.

\begin{abstract}
Rousseau, in his work The Social Contract Or Principles Of Political Right, developed the conception of state of nature and their transition to civil society, as well as an investigation of the concept of law and the function and importance of the legislator to build a just and legitimated society. In justification of some of his political and philosophical positions the philosopher makes quotations from the works of thinkers and statesmen like Montesquieu, Plato, Machiavelli, Solon and Lycurgus. Our goal at this research is to reveal the importance that arises from legal and pedagogical functions of the legislator in the Social Contract, seeking examples in the sources quoted by Rousseau.
\end{abstract}

Keywords: Rousseau. Legislator. Laws. Social Contract. Montesquieu. Machiavelli. Solon. Lycurgus. 


\section{Introdução}

Nas últimas décadas, o mercado global vem passando por constantes mudanças, em virtude das exigências pela oferta de produtos e serviços, com alto nível de qualidade e baixo custo para o consumidor final. Neste cenário, o departamento de suprimentos se destaca como fator estratégico para geração de valor agregado à organização, contribuindo em redução de custos, aumento de qualidade nos níveis de serviços e produtos, aumento da competitividade e, consequentemente, nos lucros aos acionistas.

A legitimação da sociedade ocorre através da legislação, ou seja, da construção de leis através de um pacto social em que todos se respeitam mutuamente. A elaboração destas leis é uma função árdua de um membro da sociedade que é reconhecido pela extraordinária sabedoria e superioridade moral e que, ao mesmo tempo, está alheio aos assédios das paixões humanas. Assim é inicialmente descrita a figura do legislador no Contrato Social. Entretanto, o que é ser um bom legislador? Este tema é de suma importância para o professor de filosofia, pois, num momento de discussão em sala de aula precisará argumentar lançando esta reflexão a seus alunos e orientando-os de forma histórica e com rigor filosófico às respostas e, quiçá fazê-los crer na política como forma de transformação, evitando a eleição de alguém despreparado pela simples desconfiança, desconhecimento e descrédito que o eleitor tem nos partidos políticos e seus membros.

No "Contrato Social", Rousseau, apresenta exemplos de legisladores como Licurgo e Sólon, além dos filósofos e pensadores políticos: Montesquieu, Maquiavel e Platão. Eles serviram de base para a sua pesquisa e elaboração do seu pensamento. Mergulhado no Contrato Social, compara os próprios exemplos com os dos autores que o inspiravam buscando respostas mais completas para as seguintes questões: Qual a importância das leis para a sociedade? Quais as funções e a importância do legislador? Existe alguma virtude essencial nesta função?

\section{As leis e sua importância para a sociedade}

Partindo da opinião de que "No estado de natureza, onde tudo é comum, nada devo a quem nada prometi, e não reconheço a outrem o que me é inútil” (ROUSSEAU, 2008 , p. 55). Afere-se que a ideia central do Contrato Social é recorrente nas preocupações politico-filosóficas de Rousseau, e que em síntese, trata-se de um consenso estabelecido entre as pessoas com vistas à fundação da sociedade. O pacto é o divisor de águas entre o estado de natureza e o estado civil. Este segundo é constituído artificialmente, e convencionalmente, com a renúncia dos direitos naturais de cada indivíduo em favor de direitos civis, expressão de uma vontade geral, que garantem o bem-estar, a felicidade e a paz de todos.

Cabe aqui fazer dois breves esclarecimentos, sendo o primeiro sobre o estado de natureza que, para o autor, se configura num estado de plenitude de liberdade, chamado de liberdade natural, onde prevalece a lei do mais forte. Pois, a liberdade natural só tem por limites as forças do indivíduo e a resistência de seus oponentes.

No estado de natureza, existe a justiça, em certos momentos, e a utilidade quase sempre, pois nele "nada devo a quem nada prometi e não reconheço a outrem aquilo que me é inútil”. O estado civil procura aliar as duas coisas. O grande desafio do autor é lançado na introdução do Livro I, onde diz: 
"Gostaria de pesquisar se, na ordem civil, pode existir alguma regra de administração legítima e segura, tomando os homens como são e as leis como poderiam ser. Procurarei aliar sempre, nessa pesquisa, o que o direito permite ao que o interesse prescreve, para que a justiça e a utilidade não se encontrem divididas". (ROUSSEAU, 2008, p. 15)

A problemática do Contrato Social consiste em fornecer uma formula de sociedade não abusiva, que permita à existência social e o usufruto de todos os benefícios concernentes à essência. Com o pacto social, o instinto do homem seria substituído pela justiça e daria a sua conduta a moralidade que antes lhe faltava. O individuo que existia no estado de natureza difere do individuo que se forma no estado civil, este último compõe um pacto, é uma pessoa pública, um corpo coletivo, formado com base na união de forças e interesses de diversos indivíduos. É importante esclarecer que o que diz respeito à vontade geral, esta acima das vontades individuais. Trata-se de outra vontade, resultante da união das vontades individuais, não como um somatório, nem como um repositório de vontades, mas como consenso de interesses sintetizado em um único, ou seja, não se trata de uma unanimidade, mas de uma síntese consensual baseada nas ideias dos pactuantes.

Feitos os esclarecimentos, cabe a pergunta, dentro deste contexto de pacto social - desconsiderando, ao menos a priori, o estado de natureza - "o que são as leis"? Rousseau também se faz esta pergunta na sua obra. Não por acaso, pois investigar o conceito de legislador no pensamento político de Rousseau demanda, sem sombra de dúvidas, uma reflexão anterior sobre o conceito de lei.

A contribuição de Rousseau acerca da lei é considerada original, haja vista que rompe com a tradição, posto que não se limita em saber como os indivíduos elaboram as leis, mas se preocupa em pensar sobre como as leis deveriam ser, e busca considerar a origem e a essência das mesmas, e de quem as faz. Assim, torna-se necessário compreender o significado da lei em Rousseau, para em seguida, tratar do legislador.

Após a criação da sociedade civil através do pacto social, advém a necessidade de algo que represente, garanta e conserve este pacto com reciprocidade de ações, eis aqui o campo das leis.

Montesquieu assim define lei:

“a lei, em geral, é a razão humana, que governa todos os povos da terra; e as leis políticas e civis de cada nação devem ser apenas casos particulares onde se aplica esta razão humana. Devem ser tão próprias de cada povo para o qual foram feitas, que seria um acaso muito grande, se as leis de uma nação pudessem servir a outras". (MONTESQUIEU, 2005, p. 16)

As leis não se originam sem uma causa e é a esse exame que se debruça o pensamento de Montesquieu, autor que foi estudado por Rousseau e sobre isto afirma CRETELLA que Rousseau:

"Estuda o Espírito das leis, de Montesquieu, mas enquanto este é jurista e sociólogo, Rousseau, como Filósofo, preocupa-se com a natureza e com a felicidade do homem, chegando até a política, uma vez que o homem é, como dizia Aristóteles, um animal político". (ROUSSEAU, 2008, p. 10)

Outro autor estudado por Rousseau, Maquiavel, tem o seguinte conceito de lei: "é útil e necessário que as leis de uma república deem à massa do povo um meio legal de manifestar a cólera que sente contra um cidadão" (MAQUIAVEL, 2000, p. 25). Tendo citado os pontos de vista dos autores estudados por Rousseau, cabe agora perguntar: Mas o que será, finalmente, uma 
lei? "pelo pacto social é atribuído vida ao corpo político. Trata-se, agora, de lhe dar, pela legislação, movimento e vontade [...]" (ROUSSEAU, 2008, p. 55).

A definição de lei na obra de Rousseau é original e rompe com uma tradição de aceitar as leis tais como são investigando suas relações com certas circunstâncias geográficas, ecológicas e sociais. Desta forma, abandona-se qualquer relação necessária com a lei natural. Pois, se o corpo social é fruto de uma convenção, suas leis não poderiam ter outra fonte. E o que revela os pontos de vista de Montesquieu e Maquiavel.

Rousseau rompe com este paradigma de estudar as leis como são, quando procura saber como as leis poderiam ser, tendo em conta sua origem - o estado de natureza - e sua essência humana. Ele é levado a isto pela própria problemática do Contrato Social que é a de analisar "alguma regra de administração legitima e segura, tomando os homens como são e as leis como poderiam ser" (ROUSSEAU, 2008, p. 15). E poder-se há ver a seguir que isto está presente antes mesmo da conceituação de lei. O anel mágico de Giges $^{1}$

O desejo de um pacto social [contrato social] para construir uma cidade [sociedade] justa é antigo. Desta forma encontram-se algumas similaridades entre Platão e Rousseau, existe uma história que ilustra uma delas. Numa discussão apresentada por Platão em “A República”, Glauco argumenta com Sócrates sobre justiça e apresenta uma justificativa para sua tese de que é melhor ser injusto, pois, apesar do individuo perpetrar injustiças, ele pode receber justiça ou não. Caso receba injustiças, já teria se vingado.

\footnotetext{
${ }^{1}$ Giges foi rei da Lídia, c. 687-651 a.C., depois de ter assassinado o monarca anterior, Candaules, e de ter desposado a viúva deste. Nota em (PLATÃO, 1972, p. 57).
}

Para sustentar sua argumentação, Glauco contou a história de Giges e o anel mágico.

Giges era um pastor de ovelhas do reino da Lídia. Neste reino, todos prestavam contas das suas propriedades e dos seus trabalhos ao soberano numa assembleia. Certo dia, Giges estava no pasto quando ocorreu um terremoto e uma fenda gigantesca se abriu. Passado o susto, Giges, olhando a enorme fenda, avistou uma gruta. Ele entrou na gruta e encontrou um imenso cavalo de bronze e um esqueleto que tinha um anel numa das mãos, que logo Giges pegou. No dia seguinte, aconteceu a assembleia de prestação de contas com o soberano. Giges sentou-se no meio da multidão, e em determinado momento, girou o anel no dedo anular. Neste momento as pessoas ao lado começaram a perguntar sobre ele. Giges notou que estava invisível e voltando a girar o anel, tornou-se visível novamente. De posse deste poder, Giges poderia escapar das leis e das sanções. Assim, começou a buscar satisfazer as suas necessidades e desejos particulares, sendo a primeira delas, seduzir a rainha, uma mulher bonita e desejada e a partir daí, matou o soberano e tomou posse do trono e dos bens. (PLATÃO, 1972, 56-59)

A história relatada por Glauco (PLATÃO, 1972, 56-59) ${ }^{2}$ ilustra bem quando Rousseau (2008, p. 55) diz que "Considerando-se humanamente as coisas, as leis da justiça, dada a falta de sanção natural, tornam-se vãs para os homens; só fazem o bem do mau e o mal do justo" e isso se deve precisamente porque o justo "as observa com todos, sem que ninguém as observe com ele" (ROUSSEAU, 2008, p. 55). Em síntese, foi o mesmo que Glauco quis dizer quando comentou que; todo mundo que adquira o

\footnotetext{
${ }^{2}$ A história corresponde ao trecho do diálogo platônico de 359c-360d
} 
poder de fazer o que quiser impunemente certamente usará para elevar a sua posição social, aumentar a sua riqueza, seu poder, sua gratificação sexual, prejudicando os inimigos e ajudando os amigos como julgar conveniente. Ele fala sobre a natureza sendo compelida pela lei à perversão de respeitar a justiça; e a implicação disso é que, deixados ao nosso próprio arbítrio, o ser humano é naturalmente predisposto a cometer injustiças e, por conseguinte, necessita de um artifício coletivamente construído [um pacto social], na forma do sistema legal, para produzir a conduta justa.

Alguns parâmetros foram estabelecidos no Contrato Social, antes de se definir o que é lei, entre estes, uma menção a não considerar as leis apenas como conceito metafísico, mas real e concreto, frisando a importância do fato de que, não se levando em conta o caráter humano, das questões para o qual se direciona a justiça, as leis não tenham sentido para os indivíduos.

\section{A reciprocidade e a universalidade das leis}

No entendimento de que "São, pois, necessárias convenções e leis para unir os direitos aos deveres, e conduzir a justiça ao seu objetivo". (ROUSSEAU, 2008, p. 55), merece consideração também a questão da reciprocidade - entrega da minha liberdade natural em troca da liberdade civil estabelecida através de convenção, vontade geral - que deve ser garantida pelas leis com a união dos direitos aos deveres, através do pacto social numa sanção coletiva, ou seja, de todos a todos. Pois,

“Tão logo se encontre a multidão reunida num corpo, não se pode ofender um dos membros sem atacar o corpo, menos ainda ofender o corpo sem que os membros disso se ressintam. Assim, o dever e o interesse obrigam igualmente as duas partes contratantes a se auxiliarem de forma recíproca, e os próprios homens devem procurar reunir sob essa dupla relação todas as vantagens que disso dependem" (ROUSSEAU, 2008, p. 34).

Por último a questão da universalidade das leis é abordada com a afirmação que o objeto das leis é sempre geral, ou seja, na sociedade, a lei poderá “estatuir que haverá privilégios, mas ela não poderá concedê-los nominalmente a ninguém" (ROUSSEAU, 2008, p. 56) e todos os que fizerem parte do Estado, inclusive o próprio Estado, serão submisso a ela, pois, ela será universal e representará a vontade geral estabelecida por convenção.

Sendo assim, pode-se definir a lei como sendo o ato cuja matéria sobre a qual estatui é originária da vontade geral, considerando-se o caráter humano e universal na condução da justiça ao seu objetivo, garantida a reciprocidade pela sanção coletiva estabelecida no pacto social. Na definição de Rousseau: “[...] a matéria sobre a qual se estatui é geral como a vontade que a estatui. A esse ato dou o nome de lei" (ROUSSEAU, 2008, p. 56)

A lei é de suma importância para a sociedade. Ela é a condição de associação civil que une os direitos aos deveres, a justiça e a utilidade, gerando uma reciprocidade presumida no corpo coletivo. É o que dá vida, movimentação a sociedade, sendo a representação consensual de sua vontade. Entretanto, se a lei é algo de extraordinário, o que dizer daqueles que as fazem?

\section{O que é o legislador? Qual a sua importância?}

Aqui se adentra, mais precisamente, no tema deste artigo "A importância do Legislador no Contrato Social”. Os cidadãos são capazes de julgarem por si só qual o 
consenso para elaboração de uma lei? Rousseau considerou que não, pois o povo pode ser enganado, haja vista, que naturalmente cada um buscará os seus interesses, pois, no estado de natureza "nada devo a quem nada prometi e não reconheço a outrem o que me é inútil" (ROUSSEAU, 2008, p. 55). Logo, as decisões são permeadas por certa intencionalidade egoísta.

Sólon, legislador ateniense, estudado e citado por Rousseau e ao qual é atribuída a fundação da sociedade ática, foi descrito por Aristóteles nas seguintes palavras:

"Desses legisladores, alguns só elaboraram leis, outros fundaram estados, como Licurgo e Sólon, que foram simultaneamente, legisladores e fundadores de governos" (ARISTÓTELES, [ca. 2010], p. 69)

A primeira realização de Sólon foi a lei da libertação, por ele introduzida em Atenas com a finalidade de resgatar pessoas e bens. Pois, frequentemente, os homens tomavam dinheiro emprestado mediante garantia de suas próprias pessoas, e muitos foram forçados pela pobreza a tornar-se escravos. Ele foi o primeiro a renunciar ao seu direito, uma dívida de sete talentos, cujo credor era seu pai, e assim encorajou outros a seguir-lhe o exemplo.

Entretanto, os atenienses viviam em guerra com Megara pelo domínio da ilha de Salamina, terra natal de Sólon. Após numerosas derrotas Atenas promulgou um decreto punindo com morte qualquer pessoa que propusesse o reinício da guerra salamínia.

Certo dia Sólon, que nasceu na ilha de Salamina, utilizou-se de sabedoria e dos seus versos para iniciar uma guerra de reconquista da sua ilha natal pelo povo ateniense. Ele fingiu-se de louco e saiu correndo até a Ágora com uma guirlanda na cabeça. Lá ele pediu ao arauto que se lê os seguintes versos:
"Ah! Se eu mudasse de pátria e fosse um folegândrio ou sicinita em vez de ateniense! Logo se difundiria essa fama entre os homens: os atenienses, embora sendo áticos, abandonaram Salamina" (LAERTIOS, 2008, p. 24)

Isto deixou os atenienses furiosos e eles retomaram a guerra contra os megáricos e acabaram vitoriosos. Este exemplo mostra, ao menos, algo suspeito. O legislador, contrariando a decisão do grupo de cidadãos, que chegaram ao consenso de não mais guerrear contra uma cidade, os induz - com recursos de astúcia e sagacidade literárias - a retomar os combates para reconquistar sua terra natal. Este devaneio do legislador, por mais bem intencionado que fosse, poderia ter levado a ruína da sociedade ateniense. Por certo que, no legislador idealizado por Rousseau, não ocorreria algo como tal, haja vista que este não possui nem direito legislativo nem participa do poder e que, em momento algum, se objetaria ao consenso, a vontade geral. Mas o fato é: como se pode juntar justiça e utilidade? Como garantir bemestar ao cidadão e a sobrevivência do Estado? A definição de lei em Rousseau dá respostas a muitas das perguntas que os filósofospolíticos levantaram ao longo da história. De certa forma, não seria mais relevante determinar quem deve fazer a lei, porque ela é definida como uma expressão da vontade geral aflorada do povo e, vale frisar, não se pode aceitar que um príncipe esteja acima de jurisdição da lei, pois, ele é um membro do Estado, e como tal está sujeito à lei que o regula. Além disso, a lei não pode ser considerada injusta, porque os cidadãos são o seu autor. Porém, se, com foi dito, não é mais relevante determinar quem deve fazer as leis, então, qual a função de um legislador? O que esta figura representa para o Estado e a sociedade? Outra questão que incide é, será que o povo conseguiria enxergar o que é bom e necessário, não apenas para um individuo, mas para toda a sociedade, assim como para a preservação do Estado? 
"Os particulares veem o bem que rejeitam, o povo deseja o bem que não vê. Todos igualmente necessitam de guias; é preciso obrigar uns a conformar suas vontades com sua razão; é necessário ensinar a outros o que pretendem”. (ROUSSEAU, 2008, p. 57)

Embora Rousseau atribua o poder legislativo ao povo, ele tem várias preocupações sobre o exercício da soberania. Ele acredita que o homem comum pode se encontrar cego diante dos benefícios individuais em curto prazo em detrimento da realidade dos riscos em longo prazo para o Estado e a sociedade, e ser facilmente manipulado, estando até muitas vezes inconsciente de suas próprias necessidades. Ele acredita que "A vontade geral é sempre correta, mas o julgamento que a dirige nem sempre é esclarecido" (ROUSSEAU, 2008, p. 57) e diz ainda que "Nunca se corrompe o povo, mas muitas vezes ele é enganado" (ROUSSEAU, 2008, p. 47). Neste caso, o legislador ajuda dirigindo e corrigindo as falhas de um processo legislativo popular, mantendo a soberania com o povo.

Para que a sociedade política de Rousseau funcione, os cidadãos devem priorizar a vontade geral sobre os seus interesses particulares. Esta é uma exigência muito difícil, e Rousseau reconhece que um legislador terá de ajudar as pessoas a buscar o bem comum. Desta forma, ele descreve o legislador como tendo qualidades quase divinas. Ele deve ter a inteligência e habilidade persuasiva necessária para efetuar uma mudança moral no Estado e uma transformação dos cidadãos lhes atribuindo um altruísmo patriótico que busca o bem comum e a preservação deste mesmo Estado. Muitos críticos da teoria política de Rousseau têm-se centrado sobre a impossibilidade de encontrar tal legislador que deve ser dotado, como condição sine qua non, de sabedoria e amor à pátria.
Por outro lado, não está claro se Rousseau acredita que as pessoas possam lidar com as demandas de legislar sem a orientação do legislador. O legislador ajuda as pessoas a pesar benefícios de curto prazo contra riscos em longo prazo. Ele também dá um sentido temporal e espacial ao legislar, e impede a prevalência dos interesses privados a partir da articulação da distorção da vontade geral. Estas são todas as funções essenciais do processo legislativo, e sem a ajuda do legislador, seria muito difícil para preservar o Estado e garantir a felicidade dos cidadãos.

Rousseau acredita fortemente no poder das leis, pois elas podem transformar a natureza humana, substituindo liberdade natural pela liberdade civil, e tornar $\mathrm{O}$ indivíduo parte de um todo maior. Considerando que o estado de natureza permite ao homem "fazer o que desejar", a lei lhes dará um sentido de dever cívico e moral.

Do ponto de vista metafísico, o homem é livre para fazer o que quiser, independentemente de todos os outros, ou seja, o homem é naturalmente livre. Entretanto tem como limitação as suas próprias forças e a resistência dos seus oponentes. Por outro lado, a liberdade natural é substituída pela liberdade moral no momento em que o homem se sociabiliza. Alienar direito natural para criar direito moral e político não existe na natureza, só na cultura. Na sociedade, o homem se torna livre ao reconhecer-se moralmente no outro, formando um corpo político. Isto se dá, artificialmente, através das leis, criadas a partir do pacto social, que regulamentam esta movimentação. A primeira grande função do legislador é, neste caso, transformar o homem. Como diz o autor: "Aquele que ousa empreender a instituição de um povo deve sentir-se com capacidade de, por assim dizer, mudar a natureza humana". (ROUSSEAU, 2008, p. 59) 
Quando se fala de vontade geral apreende- se que ela é sempre correta, pois deriva de uma convenção. Todavia, a questão sobre a qual insiste Rousseau é que toda união social repousa numa convenção, mas nem toda convenção é legítima. O que caracteriza a convenção legítima [contrato social] é a liberdade pública, ou seja, o homem renuncia à sua liberdade natural em favor de uma liberdade convencional na qual "ganha o equivalente de tudo o que perde e mais força para conservar o que tem" (ROUSSEAU, 2008, p. 30), e assim, permanece tão livre quanto antes. Se o homem, além das próprias necessidades naturais, obedecer também às necessidades de toda a associação que existe para conservá-lo e que ele ajudou a fundar, continuará obedecendo a si mesmo. E que "O povo, de si mesmo, sempre deseja o bem; mas nem sempre o vê, de si mesmo" (ROUSSEAU, 2008, p.57), desta forma, não sendo o povo capaz de ver por si mesmo as regras e as leis para alcançar o bem comum e a preservação do pacto social, eles necessitam de guias ou orientadores, que os mostrarão o bom caminho e os protegerão das vontades particulares, uma missão quase messiânica e tão difícil quanto empreender a instituição de um povo. Eis a necessidade do legislador dentro do pacto social.

\begin{abstract}
"Para descobrir as melhores regras de sociedade convenientes às nações, farse-ia preciso uma inteligência superior que visse todas as paixões e não provasse nenhuma; que não tivesse nenhuma relação com nossa natureza e a conhecesse no íntimo; cuja felicidade fosse independente de nós, e que, portanto. Quisesse ocupar-se da nossa; enfim que, no progresso dos tempos, procurando-se uma glória longínqua, pudesse trabalhar em um século e usufruir em outro". (ROUSSEAU, 2008, p. 59)
\end{abstract}

O conceito de legislador no Contrato Social, em alguns pontos, assemelha-se ao conceito de reis-filósofos na República de
Platão, entre as semelhanças, pode-se citar o fato de ambos possuírem inteligência $e$ caráter superior. Platão defende que os reisfilósofos são aptos por natureza à filosofia, sendo assim, também aptos às funções de governo. As razões são essencialmente duas: somente filósofos treinados possuem $\mathrm{O}$ conhecimento necessário para governar e, em segundo lugar, ele acredita que suas virtudes morais e intelectuais são superiores às dos outros. Diz Sócrates:

“[...] como estabelecemos que são os filósofos aqueles que podem chegar ao conhecimento do imutável, ao passo que os que não podem, mas erram na multiplicidade dos objetos variáveis, não são filósofos, cumpre-nos ver a quem escolheríamos para governar". (PLATÃO, 1972, p. 191)

Quanto a estas características, no Contrato Social ela é endossada pelo filósofo genebrino quando ele diz que "Para descobrir as melhores regras de sociedade convenientes às nações, far-se-ia preciso uma inteligência superior que visse todas as paixões e não provasse nenhuma [...]" (ROUSSEAU, 2008, p. 59). Este estilo de vida ascético, livre de paixões, é também muito similar a dos reisfilósofos [guardiões] de Platão. Mais uma característica importante do legislador diz respeito a forma dele se comunicar com o povo e que, neste caso, pode ser tomada como outra similaridade entre Platão e Rousseau. É sabido que Rousseau apresenta alguns elementos platônicos. Neste caso, Platão introduz o Mito dos Metais como forma de explicar ao povo porque os reis-filósofos devem governar.

De acordo com Platão, a verdadeira razão é muito complicada e avançada - em termos metafísicos - para ser dita ao povo, desta forma uma história deve ser contada com audácia e eloquência persuasiva: "Concordo contigo que eu tinha muitos bons motivos; mas ouve o resto da fábula: $\mathrm{Na}$ cidade sois todos irmãos [...]" (PLATÃO, 
1972, p.111). Desta forma segue-se uma fábula onde todos são oriundos da terra, sendo alguns feitos de certos metais preciosos como o ouro e por isso devem governar. Rousseau reconhece essa necessidade de usar artifícios linguísticos para se comunicar com o povo quando diz: “[...] os sábios, desejosos de falarem ao vulgo a sua linguagem, não a deste, não conseguiriam fazer-se entender. Ora, há mil espécies de ideias impossíveis de traduzir na língua do povo [...]" (ROUSSEAU, 2008, p. 61). Rousseau conclui que a vontade geral e os benefícios em longo prazo estão fora da compreensão do povo enquanto multidão e que cada um entende do governo aquilo que vai de encontro com suas particularidades e não com o bem comum, logo, o legislador deve saber comunicar as leis ao povo utilizando-se de perspicácia de raciocino e linguagem adequada ao público para o qual se dirige. Este artifício é aconselhado por Platão através do Mito dos Metais e, como narrado acima, foi usado por Sólon através de versos que incitaram o povo ateniense a continuar a guerra de reconquista de Salamina.

Todavia, no seu pensamento político, Rousseau demonstra a importância da vontade geral e, de fato, é esta ideologia política moderna que separa Rousseau de Platão. O rei-filósofo platônico, Sólon e o legislador de Rousseau são resultados de diferentes períodos de tempo e tradições filosóficas e sendo assim, é possível apontar algumas divergências entre estes elementos. Uma delas pode ser o propósito pelo qual os diferentes legisladores ocupam suas posições. Rousseau chama o legislador de "um homem extraordinário” (ROUSSEAU, 2008, p. 60) e ele ainda afirmava que seriam necessários deuses para dar leis aos homens. Com isto, parece-nos conferir um caráter quase nato à função do legislador que comporia uma missão, se não acima da força humana, ao menos difícil de empreender; alias como citado por ele mesmo quando diz: "na obra da legislação duas coisas na aparência incompatíveis: um empreendimento acima da força humana, e, para executá-lo, uma autoridade que nada representa" (ROUSSEAU, 2008, p. 61)

Platão por sua vez acredita que o reifilósofo é preparado para assumir esta posição, ele procura iluminar-se e, assim, esclarecer a sociedade ordenando através da filosofia os fins superiores da vida.

Ele cita o seguinte: "Queres saber já de que maneira se formarão homens dessa qualidade e como é que uma pessoa os fará ascender até a luz [...]" (PLATÃO, 1972, p. 325). Rousseau afirma contrariamente a isso que: "Cansa demais, segundo se diz, ensinar os jovens príncipes a reinar, e não me parece que tal educação lhes seja proveitosa". (ROUSSEAU, 2008, p. 98)

E diz ainda:

"Mas, se consoante Platão, o rei, por natureza, é um personagem tão raro, quantas vezes concorrem a Natureza e a fortuna para coroá-lo? E se a educação real corrompe necessariamente os que a recebem, que se deve esperar de uma seqüência de homens distinguidos para reinar?". (ROUSSEAU, 2008, p. 99)

Assim, pode-se aferir que a assunção a esta posição de legislador não é uma coisa que vem apenas de um caráter nato - como julgaria Platão com o Mito dos Metais onde os reis-filósofos seriam os filhos feitos de ouro - nem de uma educação para o "governar".

Outra coisa nos chama atenção é a forma com que o rei-filósofo se dirige ao povo, através de ordens razoáveis, esclarecimentos (intermediadas pela razão). O legislador de Rousseau carece de vontade, tempo e meios para fazê-lo, até porque ele é "uma autoridade que nada representa" (ROUSSEAU, 2008, p. 61). Em vez de esclarecer, ele deve persuadir. Em contraste 
com os reis-filósofos, para os legisladores, não é uma questão de me ensinar o que é justiça, mas de mostrar o que há de interessante em ser justo, através de outros métodos que a razão, o legislador persuade as pessoas a aceitar a sua decisão sobre a lei, ou seja, "o legislador não pode empregar nem a força nem o raciocínio, é basilar que recorra a uma autoridade de outra ordem, que possa conduzir sem violência e persuadir sem convencer" (ROUSSEAU, 2008, p. 61). "Desses legisladores, alguns só elaboraram leis, outros fundaram estados, como Licurgo e Sólon, que foram simultaneamente, legisladores e fundadores de governos" (ARISTÓTELES, [ca. 2010], p. 69)

Um legislador dos mais elogiados por Rousseau é o lendário Licurgo que, segundo Rousseau, fez com que Esparta renascesse, por assim dizer, das cinzas e readquirisse o vigor da juventude, saindo dos braços da morte. Este também teve como grande ato institucional com respeito às opiniões individuais dentro de um contexto público.

"Portanto, a fim de se ter o perfeito enunciado da vontade geral, importa não haja no Estado sociedade parcial e que cada cidadão só manifeste o próprio pensamento. Foi assim a única e sublime instituição do grande Licurgo". (ROUSSEAU, 2008, p. 48)

\section{A legislação de Licurgo era o contrário do que os gregos entendiam} costumeiramente como leis. Não se tratava de uma compilação de leis particularizadas, civis e públicas, e sim de uma tradição oral válida da qual apenas algumas leis fundamentais e solenes eram escritas. A reverência à vida pública mais do que a privada por parte de Licurgo fica por conta de uma dessas tradições, as assembleias populares mencionadas por Plutarco:

\footnotetext{
"Naquele tempo, as assembleias do povo se realizavam entre dois rios, pois não havia sala para reunir o grande conselho, nem praça que fosse de outro
}

modo embelezada nem ornada, porque Licurgo estimava que isso de nada serviria para bem deliberar e escolher bom conselho, e sim para prejudicar [...]”. (PLUTARCO, 1985, p. 102)

Por certo, uma grande virtude de Licurgo foi o patriotismo, entendido aqui como amor a pátria manifestado pelo desejo de felicidade dos cidadãos e de perpetuação do Estado. Assim define JAEGER:

"Licurgo habituava os cidadãos a não terem nem desejo nem capacidade para fazerem vida privada. Pelo contrário, levava-os a se consagrarem à comunidade e agruparem-se em torno do seu senhor libertando-os do culto do eu pessoal, para pertencerem inteiramente à pátria" (JAEGER, 1994, p. 113)

Para Rousseau o legislador "não deve ele fundar o julgamento sobre o que vê, mas sobre o que prevê, nem tanto se deter no estado atual da população, mas sim no que ela virá naturalmente a ser" (ROUSSEAU, 2008, p. 67) assim também é exaltada "a obra da sabedoria previdente de Licurgo, o qual, como Sócrates e Platão, dava maior importância à força da educação e à formação da consciência dos cidadãos do que às prescrições escritas" (JAEGER, 1994, p. 112). Quiçá assim, o legislador possa fazer com que os homens sejam, antes das leis, o que devem ser graças a elas.

\section{Considerações Finais}

Existe certa dificuldade em apreciar a obra de Rousseau e, em especial, Do Contrato Social permeado de uma romântica ideologia político-religiosa, chegando-se a pensar que o autor, quando descreve seu legislador, trata de uma figura messiânica de um semideus, ou seja, olhando para vida pessoal, apontar-se-ia apressadamente, a de Jesus Cristo. A verdade é que, se o pacto social é um divisor de águas, o legislador representa a passagem dos 
princípios para a aplicação. Se as leis são as condições de associação civil, o legislador do contrato social é conceito basilar para a realização desta sociedade civil. É indivíduo imbuído de uma única virtude capital e essencial, o amor à pátria. Virtude esta capaz de gerar outras tantas nobres como a justiça e a moderação. Ele é o guia, o pedagogo, o preceptor de Emílio; aquele que vê além, que representa o retorno à caverna metaforizado por Platão.

Nesta perspectiva, o seu educar toma o significando de instruir, orientar, guiar um povo para que não seja enganado e tenha um caráter de alteridade e consciência da vida pública de forma que a viva na busca pela felicidade e pelo bem comum, constituindo uma grande obra deste legislador que, sendo capaz de executá-la sem se deixar levar pelas paixões humanas e não desfrutando do poder que da função advém, será verdadeiramente "sob todos os aspectos, um homem extraordinário no Estado" (Rousseau, 2008, p. 60).

\section{Referências Bibliográficas}

1. ABBAgnAnO, Nicola. Dicionário de

Filosofia. Tradução Alfredo Bossi. 5 ed. São

Paulo: Martins Fontes, 2007

2. ARAÚJO, Luiz Alberto David. Curso de

Direito Constitucional. 14 ed. São Paulo:

Saraiva, 2010

3. ARISTÓTELES. Ética a Nicômaco.

Tradução, introdução e notas de Edson Bini.

$3^{\mathrm{a}}$ ed. Bauru: Edipro, 2009

4. ARISTÓTELES. A Política. Tradução Nestor Silveira Chaves. São Paulo: Escala, [ca. 2010]
5. BAUMAN, Zygmunt. Legisladores e intérpretes: sobre modernidade, pósmodernidade e intelectuais. Tradução Renato Aguiar. Rio de Janeiro: Zahar, 2010

6. BITTAR, Eduardo Carlos Bianca. Curso de Filosofia do Direito. $4^{a}$ ed. São Paulo: Atlas, 2006

7. BITTAR. Eduardo Carlos Bianca. Curso de filosofia política. 4 ed. São Paulo: Atlas, 2011

8. JAEGER, Werner Wilhelm. Paidéia: a formação do homem grego. Tradução Arthur M. Parreira. 3 ed. São Paulo: Martins Fontes, 1994

9. LAERTIOS, Diogenes. Vidas e doutrinas dos filósofos ilustres. Tradução Mario da Gama Kury. Brasília: UNB, 2008

10. MAQUIAVEL, Nicolau. Comentários sobre a primeira década de Tito Lívio. Tradução Sérgio Bath. Brasília: Editora UnB, 2000

11. MARUYAMA, Natalia. A contradição entre o homem e o cidadão: consciência e política segundo J.-J. Rousseau. São Paulo: Humanitas, 2001

12. MONTEAGUDO. Ricardo. Entre o direito e a história: a concepção do legislador em Rousseau. São Paulo: Editora UNESP, 2006

13. MONTESQUIEU, Charles Louis de. O Espírito das Leis. Tradução Cristina Murachco. São Paulo: Martins Fontes, 2005 
14. MORA, José Ferrater. Dicionário de

Filosofia. Tradução Roberto Leal Ferreira, Álvaro Cabral. $4^{\text {a }}$ ed. São Paulo: Martins Fontes, 2001

15. PLATÃO. A República. Tradução Maria Helena da Rocha Pereira. Lisboa: Fundação Calouste Gulbenkian, 1972

16. PLUTARCO. Vidas paralelas. Tomo I. Tradução Aurélio Pérez Jiménez. Madrid: Editorial Gredos, 1985

17. PURSHOUSE. Luke. A República de Platão: um guia de leitura. Tradução Luciana Pudenzi. São Paulo: Paulus, 2010

18. REALE, Giovanni. História da filosofia: filosofia pagã antiga. v. 1. Tradução Ivo Storniolo. São Paulo: Paulus, 2003
19. ROUSSEAU, Jean-Jacques. Discurso sobre a origem e os fundamentos da desigualdade entre os homens. Tradução Paulo Neves. Porto Alegre: L\&PM, 2009 20. ROUSSEAU, Jean-jacques. Do contrato social: princípios do direito político. Tradução de Agnes Cretella e José Cretella Júnior. São Paulo: Revista dos Tribunais, 2008

21. SOETARD, Michel. Jean-Jacques Rousseau. Tradução Verone Lane Rodrigues Doliveira. Recife: Fundação Joaquim Nabuco, Editora Massangana, 2010 22. WEFFORT. Francisco. Clássicos da Política. Vol. 1.14 ed. São Paulo: Ática, 2006 23. WEFFORT, Francisco. O que é deputado? Col. Primeiros passos. São Paulo: Brasiliense, 1986. 